\title{
Bioequivalence of Trimetazidine Modified Release Tablet Formulations Assessed in Indonesian Subjects
}

Yahdiana Harahap*, Budi Prasaja MM, Windy Lusthom, Hardiyanti, Fahmi Azmi, Vita Felicia and Lia Yumi Yusvita

Faculty of Pharmacy University of Indonesia, Depok, West Java, Indonesia

\begin{abstract}
This study was conducted in order to compare the bioavailability of two modified release tablets containing 35 $\mathrm{mg}$ of trimetazidine. Twenty-four subjects were enrolled in a single center, randomized, single dose, open label, two-way crossover study with a one-week washout period. Plasma samples were collected up 48 hours following drug administration and trimetazidine was determined by liquid chromatography-tandem mass spectrometry (LCMS/MS) method with turboionspray mode. Pharmacokinetic parameters used for bioequivalence assessment were $\mathrm{AUC}_{0-\mathrm{t}}, \mathrm{AUC}_{0-\infty}$ and $\mathrm{C}_{\max }$. The $90 \%$ confidence intervals obtained by analysis of variance for $A U C_{0-t}, A C_{0-\infty}$ and $C_{\max }$ were $94.89-105.15 \%, 94.85-105.23 \%, 93.31-107.36 \%$, respectively. These results were all within the range of $80.00-125.00 \%$. Bioequivalence between formulations was concluded both in terms of rate and extent of absorption.
\end{abstract}

Keywords: Angina pectoris; Bioequivalence; Modified release; Pharmacokinetic; Trimetazidine

\section{Introduction}

Trimetazidine, $1-(2,3,4$-Trimethoxybenzyl) piperazine dihydrochloride, is the first known 3-ketoacyl coenzyme A thiolase inhibitor. It is a metabolic agent with anti ischemic and anti anginal properties [1]. Trimetazidine inhibits mitochondrial long-chain 3-ketoacyl coenzyme a thiolase, so that shifts the cardiac energy metabolism from fatty acid oxidation to glucose oxidation [2]. This result is protection of this ischemic heart [3].

Trimetazidine reaches the peak plasma concentration in 5 hours after oral administration of a tablet. During a 24-hours study, the plasma levels are equal to or greater than $75 \%$ of the maximum concentration for 11 hours, while the apparent volume of distribution is $4.8 \mathrm{~L} / \mathrm{kg}$. Trimetazidine is excreted primarily through the kidneys, $79-84 \%$ of administered radioactivity appearing in the urine at 24 hours of which at least $60 \%$ was due to unchanged trimetazidine. The mean half-life of trimetazidine is $7.81 \pm 2.60$ hours in young healthy subjects and $11.7 \pm$ 2.33 hours in the elderly subjects $[4,5]$.

A modified release tablet containing $35 \mathrm{mg}$ of trimetazidine has been developed in order to maintain sustained 24-hour coverage with only one tablet in the morning and one in evening. After multiple dose administration of Trimetazidine MR $35 \mathrm{mg}$ in young healthy subjects, Trimetazidine reaches peak plasma concentration $\left(\mathrm{C}_{\max }\right)$ about $91.2 \pm$ $13.1 \mu \mathrm{g} / \mathrm{L}$ in range 2.0-6.0 hours $[4,6]$.

Trimetazidine is generally better tolerated than calcium antagonist and beta-blockers. There is also no evidence that long term therapy can lead to tolerance as observed with nitrate therapy. Drowsiness and mild gastrointestinal disorders such as nausea, heartburn, and diarrhea are the most frequently reported adverse reactions, but their overall incidence is low [6-8].

This study is conducted to compare the bioavailability of two trimetazidine modified-release products in healthy Indonesian subjects.

\section{Subjects, Materials and Methods}

\section{Ethic consideration}

The protocol study was reviewed by the Committee of The Medical
Research Ethics of the Faculty of Medicine, University of Indonesia (Jakarta, Indonesia) and was approved by the National Agency of Drug and Food Control (Jakarta, Indonesia). This study was conducted in compliance with the ethical principles of the Declaration of Helsinki for biomedical research involving human subjects and Good Clinical Practice (GCP). All participants signed a written informed consent after they had been informed of the nature and details of the study in accordance with Indonesian Guidelines for Bioequivalence Studies.

\section{Study design}

The study was a single-dose, open-label, randomized two-way crossover design under fasting period with one week wash out period. Subjects were randomized to one of the two sequences to receive the formulations according to randomization scheme. Based on previous study, the sample size $\mathrm{n}=24$ subjects was sufficient to ensure power of $80 \%$ for correctly concluding bioequivalence under the following assumption: $\mathrm{a}=0.05,0.95<\mu \mathrm{T} / \mu \mathrm{R}<1.05$ and an intra-subject variability of $20 \%$ [9].

\section{Subjects}

Twenty-four subjects (21 males and 3 females) were participated in this study. The demographic data of twenty-four subjects are shown in table 1. Subjects were selected after passing a clinical screening procedure including a physical examination, ECG and clinical laboratory tests (hemoglobin, hematocrit, WBC, platelets, WBC differential, blood urea nitrogen, sGPT, sGOT, alkaline phosphatase, total bilirubin, total protein, fasting glucose, albumin, total cholesterol, creatinine, urine analysis, pregnancy test only for female subjects and negative results of Hepatitis B, Hepatitis C and HIV. Subjects were excluded if they had a history of the hepatic, renal and cardiovascular

*Corresponding author: Yahdiana Harahap, Faculty of Pharmacy University of Indonesia, Depok, West Java, Indonesia, E-mail: yahdiana03@yahoo.com

Received February 25, 2013; Accepted March 27, 2013; Published April 02, 2013

Citation: Harahap Y, Budi Prasaja MM, Lusthom W, Hardiyanti, Azmi F, et al (2013) Bioequivalence of Trimetazidine Modified Release Tablet Formulations Assessed in Indonesian Subjects. J Bioequiv Availab 5: 117-120. doi:10.4172/ jbb.1000144

Copyright: (c) 2013 Harahap Y, et al. This is an open-access article distributed under the terms of the Creative Commons Attribution License, which permits unrestricted use, distribution, and reproduction in any medium, provided the original author and source are credited. 


\begin{tabular}{|l|l|l|}
\hline & Mean $( \pm$ SD) Value & Range \\
\hline Ages (years) & $28.0 \pm 5.8$ & $19-47$ \\
\hline Weight $(\mathrm{kg})$ & $60.6 \pm 10.6$ & $41-81$ \\
\hline Height $(\mathrm{m})$ & $168.8 \pm 8.0$ & $149-181$ \\
\hline
\end{tabular}

Table 1: Demographic data for trimetazidine bioequivalence study in 24 subjects.

system, taken alcohol or other medications for a long period of time, had hypersensitivity to trimetazidine, had received any investigation drug within four weeks (or suitable longer period for slowly eliminated drugs) of enrollment and donation or loss more than $450 \mathrm{ml}$ of blood within 3 months prior to the screening of the study.

\section{Drug administration and sampling}

Subjects were confined to clinical unit of Clinisindo Laboratories one night before study to assure the fasting condition (10 hours before drug administration). On the study day, subjects were given one tablet of either product with $240 \mathrm{ml}$ of water. No food was allowed until 4 hours after dose administration.

Water intake was allowed 2 hours after the dose $(240 \mathrm{ml}$ of water for each subject) and 4 hours after the dose ( $480 \mathrm{ml}$ of water for subjects). Standard meals were served at 4 hours ( \pm 939 calories) and 11 hours ( \pm 858 calories), snacks were served at 9 hours ( \pm 165 calories) after drug administration. Total calories were calculated by nutritionist.

Blood pressure, heart rate, body temperature and adverse events were monitored during blood sampling. Nine $\mathrm{ml}$ of the venous blood were collected at pre dose, $0.5,1,2,3,4,5,6,7,8,10,12,16,24,36$ and 48 hours after drug administration in the heparinized tubes. After blood separation, plasma was frozen at $-20^{\circ} \mathrm{C}$ until analysis.

After one week wash out period, subjects returned to Clinisindo Laboratories and the blood sample analysis was repeated in the second period in the same manner to complete the crossover design.

\section{Analytical method}

The concentration of Trimetazidine in plasma was determined using LC-MS/MS method with Turbo Ion Spray mode. Propranolol was used as the internal standard. The method has already been validated in terms of selectivity, sensitivity, linearity, accuracy and precision, recovery and stability and also been verified just before being used in study. The limit of quantification for Trimetazidine was $0.5 \mathrm{ng} /$ $\mathrm{mL}$. Calibration curves were prepared by spiking blank plasma with trimetazidine at concentrations of $0.50,1.00,2.50,5.00,10.00,25.00$, $50.00,100.00$ and $200 \mathrm{ng} / \mathrm{mL}$. Quality control samples were prepared by spiking blank plasma with $1.20,80.00$ and $160.00 \mathrm{ng} / \mathrm{mL}$. The best linear fit and least-squares residual for the calibration curve were achieved with $1 / \mathrm{x}^{2}$ weighing factor.

Liquid-liquid extraction method was investigated and evaluated for good sensitivity. The recoveries of Trimetazidine were $54.29 \%, 54.22 \%$, and $54.98 \%$ at low, medium, and high QC samples. The analytical separation was performed on a Synergi $4 \mu$ POLAR- RP-80A, 50×2.00 $\mathrm{mm}, 4 \mu \mathrm{m}$ (Phenomenex ${ }^{\circ}$, USA) and protected by guard column AQ C18, $4 \times 2.0 \mathrm{~mm}$ (Phenomenex, USA). The mobile phase used gradient of $0.1 \%$ formic acid in acetonitrile (mobile phase A) and $0.1 \%$ formic acid in water contains $10 \mathrm{mM}$ ammonium acetate (mobile phase B). A gradient was employed starting at $88 \%$ B for one minute then $50 \%$ B for 2 minutes and re-equilibrated at $88 \%$ B for 1.5 minutes. The flow rate was pumped $0.6 \mathrm{~mL} / \mathrm{min}$. The column temperature was maintained at $40^{\circ} \mathrm{C}$.
Briefly, a $1 \mathrm{~mL}$ of human plasma in polypropylene tube was added with Propranolol (internal standard). After mixing, $200 \mu \mathrm{L}$ of $1 \mathrm{M}$ $\mathrm{NaOH}$ and $5 \mathrm{~mL}$ of ethyl acetate were added and vortex mixed for 1 minute. The mixture was centrifuged at $3000 \mathrm{rpm}$ for $10 \mathrm{~min}$. The organic phase was removed and evaporated to dryness under vacuum at $60^{\circ} \mathrm{C}$ for $30 \mathrm{~min}$. The residue was reconstituted with methanol:water (1:1). A volume of $15 \mu \mathrm{L}$ aliquot was injected into the LC-MS/MS system. Multiple reaction monitoring (MRM) in positive ion mode was used to monitor transitions at $\mathrm{m} / z 267.2 \rightarrow 181.1$ for trimetazidine and $m / z 260.2 \rightarrow 116.2$ for the internal standard. The optimal MS parameters were follows: curtain gas $40 \mathrm{psi}$, CAD 5 psi, spray voltage $4500^{\circ} \mathrm{C}$, temperature of turbo ion spray $300^{\circ} \mathrm{C}$, GS1 50 psi, and GS2 60 psi.

\section{Safety evaluation}

Analysis of safety-related data was considered using the more common adverse events which occurred after initiation of study treatment and supported by detailed tabulations and analysis.

\section{Pharmacokinetic and statistical analysis}

The bioequivalence was determined using the primary parameters, $\mathrm{AUC}_{0-\mathrm{t}}, \mathrm{AUC}_{0-\infty}, \mathrm{C}_{\max }$. The maximum plasma concentration $\left(\mathrm{C}_{\max }\right)$ and time to reach maximum plasma concentration $\left(\mathrm{t}_{\max }\right)$ were obtained directly by inspection of the individual drug plasma concentration time data, and were used as measures of rate of absorption. The area under the plasma concentration time curve up to the last time $(\mathrm{t})$ showing a measurable concentration $\left(\mathrm{C}_{\mathrm{t}}\right)$ of the analyte $\left(\mathrm{AUC}_{0-\mathrm{t}}\right)$ was calculated using the trapezoidal rule. The elimination rate constant $\left(\mathrm{K}_{\mathrm{e}}\right)$ was calculated by the technique of least-squares regression from the data of the last 3-8 points of each plasma concentration data curve. The $\mathrm{AUC}_{0-\infty}$ values were determined by adding the quotient of $\mathrm{C}_{\mathrm{t}}$ and the appropriate $\mathrm{K}_{\mathrm{el}}$ to the corresponding $\mathrm{AUC}_{0-\mathrm{t}}$, that is:

$$
\mathrm{AUC}_{0-\infty}=\mathrm{AUC}_{0-\mathrm{t}}+\mathrm{C}_{\mathrm{t}} / \mathrm{K}_{\mathrm{el}}
$$

Where, $\mathrm{C}$ is the estimated last plasma concentration. The apparent elimination half-life $\left(\mathrm{t}_{1 / 2}\right)$ of trimetazidine in plasma was calculated by using the following equation:

$$
\mathrm{t}_{1 / 2}=(\ln 2) / \mathrm{K}_{\mathrm{el}}
$$

For the parameters of $\mathrm{AUC}_{0-\mathrm{t}}, \mathrm{AUC}_{0-\infty}$ and $\mathrm{C}_{\max }$ a multiplicative model was assumed, and analysis of variance (ANOVA) was applied using the respective ln-transformed data. For estimation of bioequivalence the $90 \% \mathrm{CI}$ of the geometric mean ratio test/reference $(\mathrm{T} / \mathrm{R})$ for $\mathrm{AUC}_{0-\mathrm{t}}, \mathrm{AUC}_{0-\infty}$ and $\mathrm{C}_{\max }$ were calculated assuming a multiplicative model. The accepted bioequivalence range for these parameters was $80.00-125.00 \%$. All statistical analyses were performed using EquivTest version 2.0 software (Statistical Solution, Cork, Ireland).

\section{Results}

\section{Clinical observation}

Both of trimetazidine formulations were well-tolerated at the administered dose and no significant adverse clinical events were observed (Figure 1). Eleven out of 24 subjects experienced 21 adverse events during the study. All adverse events were of mild intensity. There were no serious adverse events. However, all events were resolved completely. The disposition of adverse events is shown in table 2 . The causality was assessed by the study physician for all adverse events. 
Citation: Harahap Y, Budi Prasaja MM, Lusthom W, Hardiyanti, Azmi F, et al. (2013) Bioequivalence of Trimetazidine Modified Release Tablet Formulations Assessed in Indonesian Subjects. J Bioequiv Availab 5: 117-120. doi:10.4172/jbb.1000144

\section{Pharmacokinetic evaluation}

Twenty-four subjects were available for pharmacokinetic evaluation. The mean trimetazidine concentrations versus time profiles for both formulations are shown in figure 2. The pharmacokinetic parameters were used to assess the bioequivalence of the test formulation versus the reference were $\mathrm{AUC}_{0-\mathrm{t}}, \mathrm{AUC}_{0-\infty}$ for the extent of the absorption and $\mathrm{C}_{\max }$ and $\mathrm{t}_{\max }$ for the rate of absorption. Descriptive statistics of the pharmacokinetic parameter for trimetazidine test and reference are summarized in table 3 where the geometric mean values and the range for the $\mathrm{AUC}_{0-\mathrm{t}}, \mathrm{AUC}_{0-\infty}, \mathrm{C}_{\max }$ and $\mathrm{t}_{1 / 2}$ values obtained for each formulation are shown. The pharmacokinetic characteristic $t_{\max }$ was presented as mean values. For trimetazidine, the mean obtained values for test and reference products were 61.79 and $61.74 \mathrm{ng} / \mathrm{mL}$ for $\mathrm{C}_{\max } ; 762.09$ and 762.94 ng.h/mL for $\mathrm{AUC}_{0-\mathrm{t}} ; 771.87$ and $772.62 \mathrm{ng} . \mathrm{h} /$ $\mathrm{mL}$ for $\mathrm{AUC}_{0-\infty}$. The median $\mathrm{t}_{\max }$ for both formulations was $5.00 \mathrm{~h}$.

\section{Discussion}

Bioequivalence study conducted to ensure whether the generic. Two medicinal products are bioequivalent if they are pharmaceutically equivalent or pharmaceutical alternatives or a copy product is interchangeable to innovator products. The aim of the randomized, single blind, two-period, cross over study with a one week washout period, was to evaluate the bioavailability of the test and the reference

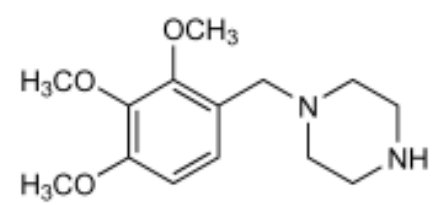

Figure 1: Chemical Structure of Trimetazidine.

\begin{tabular}{|l|l|l|}
\hline Causal relation to study drug & Events & Total \\
\hline \multirow{4}{*}{ Related } & Sleepy & 5 \\
\hline & Nausea & 3 \\
\hline & Heartburn & 2 \\
\hline \multirow{2}{*}{ Possible } & Dizziness & 3 \\
\hline Unrelated & Diarrhea & 4 \\
\hline Total & Micturition & 1 \\
\hline & Migraine & 1 \\
\hline & Fatigue & 2 \\
\hline
\end{tabular}

Table 2: Disposition of adverse events.

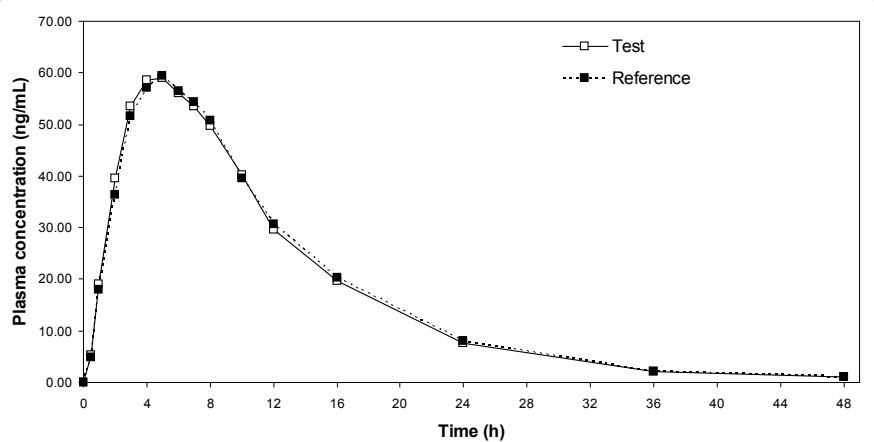

Figure 2: Arithmetic mean plasma concentration-time profiles of trimetazidine after a single dose of two $35 \mathrm{mg}$ trimetazidine modified released tablets of two different formulations.

\begin{tabular}{|l|c|c|}
\hline Parameter & Test Formulation & Reference Formulation \\
\hline $\mathrm{C}_{\text {max }}(\mathrm{ng} / \mathrm{mL})$ & & \\
\hline Geometric Mean & 61.79 & 61.74 \\
\hline Range & $32.82-104.34$ & $35.86-105.54$ \\
\hline $\mathrm{AUC}_{0-\mathrm{t}}(\mathrm{ngxh} / \mathrm{mL})$ & & \\
\hline Geometric Mean & 762.09 & 762.94 \\
\hline Range & $369.13-1435.91$ & $393.68-1426.05$ \\
\hline AUC ${ }_{0-\infty}(\mathrm{ng} \mathrm{gh} / \mathrm{mL})$ & & \\
\hline Geometric Mean & 771.87 & 772.62 \\
\hline Range & $374.11-458.57$ & $397.46-1465.44$ \\
\hline $\mathrm{t}_{1 / 2}(\mathrm{~h})$ & & \\
\hline Geometric Mean & 6.46 & 6.42 \\
\hline Range & $4.51-10.41$ & $4.56-8.54$ \\
\hline $\mathrm{t}_{\text {max }}(\mathrm{h})$ & & \\
\hline Median & 5.00 & 5.00 \\
\hline Range & $3.00-8.00$ & $3.00-7.00$ \\
\hline
\end{tabular}

Table 3: Mean pharmacokinetic parameters for trimetazidine after administration of the two formulations to 24 subjects.

\begin{tabular}{|l|c|c|}
\hline Parametric Analysis & T/R Point Estimate & Confidence Limits \\
\hline $\mathrm{C}_{\max }$ & 100.09 & $93.31-107.36$ \\
\hline AUC $_{0-\mathrm{t}}$ & 99.89 & $94.89-105.15$ \\
\hline $\mathrm{AUC}_{0-\infty}$ & 99.90 & $94.85-105.23$ \\
\hline $\mathrm{t}_{1 / 2}$ & 100.65 & $95.79-105.74$ \\
\hline
\end{tabular}

Table 4: Statistical evaluation of $A \cup C_{0-T}, A C_{0-\infty}, C_{\max }$ and $t_{1 / 2}$ for trimetazidine of two formulations from 24 subjects.

trimetazidine modified release tablet administered as $35 \mathrm{mg}$ single oral dose each.

For this study, $\mathrm{AUC}_{0-\mathrm{t}}, \mathrm{AUC}_{0-\infty}, \mathrm{C}_{\max }$ and $\mathrm{t}_{1 / 2}$ were defined as the main target parameters in order to assess possible bioequivalence between both preparations. The $90 \%$ confidence interval of the relative bioavailability should be within an acceptance interval of 80.00 $125.00 \%$. As shown in table 3 , the results of the statistical evaluation for $90 \%$ confidence interval of $\mathrm{AUC}_{0-\mathrm{t}}, \mathrm{AUC}_{0-\infty}, \mathrm{C}_{\max }$ and $\mathrm{t}_{1 / 2}$ for trimetazidine were all within the bioequivalence acceptance limit of $80.00-125.00 \%$ [10] and no significant differences were found for $t_{\text {max }}$ as analyzed by Wilcoxon sign rank test (Table 4).

The mean ratio of $\mathrm{AUC}_{\mathrm{t}-\infty} / \mathrm{AUC}_{0-\infty}$ for all individuals and for both products were around $1 \%$, indicating an adequate sampling time since the extrapolated portion of the total AUC was $<20 \%$. The median $t_{\text {max }}$ for both formulations $(5 \mathrm{~h}$ ) was comparable with data reported in the literature after administration of trimetazidine modified release tablet [6].

The intra subject variability of $\mathrm{AUC}_{0-\mathrm{t}}$ for trimetazidine was $10.34 \%$. Considering this result the sample size of 24 subjects was sufficient in order to conclude bioequivalence with the power of $80 \%$ at the $5 \%$ nominal level [9].

The safety evaluation report showed that both trimetazidine formulations were well-tolerated at the administered dose and no significant adverse clinical events were observed. 
Citation: Harahap Y, Budi Prasaja MM, Lusthom W, Hardiyanti, Azmi F, et al. (2013) Bioequivalence of Trimetazidine Modified Release Tablet Formulations Assessed in Indonesian Subjects. J Bioequiv Availab 5: 117-120. doi:10.4172/jbb.1000144

In conclusion, the two trimetazidine formulations were equivalent with respect to the rate and extent of absorption and it can be assumed to be therapeutically equivalent and exchangeable in clinical practice.

\section{Acknowledgement}

This study was supported by PT. Novell Pharmaceutical Laboratories, Jakarta, Indonesia

\section{References}

1. Marzilli M (2001) Trimetazidine: a metabolic agent for the treatment of stable angina. Eur Heart J Suppl 3: 12-15.

2. Kantor PF, Lucien A, Kozak R, Lopaschuk GD (2000) The antianginal drug trimetazidine shifts cardiac energy metabolism from fatty acid oxidation to glucose oxidation by inhibiting mitochondrial long-chain 3-ketoacyl coenzyme A thiolase. Circ Res 86: 580-588.

3. Napoli PD (2008) Anti-ischemic cardioprotection with trimetazidine. Heart Metab 41: 25-29.

4. Barre J, Ledudal P, Oosterhuis B, Brakenhoff JP, Wilkens G, et al. (2003) Pharmacokinetic profile of a modified release formulation of trimetazidine (TMZ
MR $35 \mathrm{mg}$ ) in the elderly and patients with renal failure. Biopharm Drug Dispos 24: $159-164$

5. Jackson PJ, Brownsill RD, Taylor AR, Resplandy G, Walther B, et al. (1996) Identification of trimetazidine metabolites in human urine and plasma. Xenobiotica 26: 221-228.

6. Candranipapongse W, Chatsiricharoenkul S, Ruangnapa T, Ngokpol S Sathirakul K (2011) Bioequivalence study of two formulations of $35 \mathrm{mg}$ trimetazidine modified release tablets in healthy Thai subjects under fasting and fed conditions. J Bioequiv Availab 3: 52-55.

7. McClellan KJ, Plosker GL (1999) Trimetazidine. A review of its use in stable angina pectoris and other coronary conditions. Drugs 58: 143-157.

8. Belardinelli R (2000) Trimetazidine and the contractile response of dysfunctional myocardium in ischaemic cardiomyopathy. Rev Port Cardiol 19 Suppl 5: V3539.

9. Diletti E, Hauscke D, Stenijans VW (1991) Sample size determination for bioequivalence assessment by means of confidence intervals. Int $\mathrm{J}$ Clin Pharmacol Ther Toxicol 30: 51-58

10. CHMP Committee for Medicinal Products for Human Use (2010) Guideline on the Investigation of Bioequivalence. EMEA, London. 